
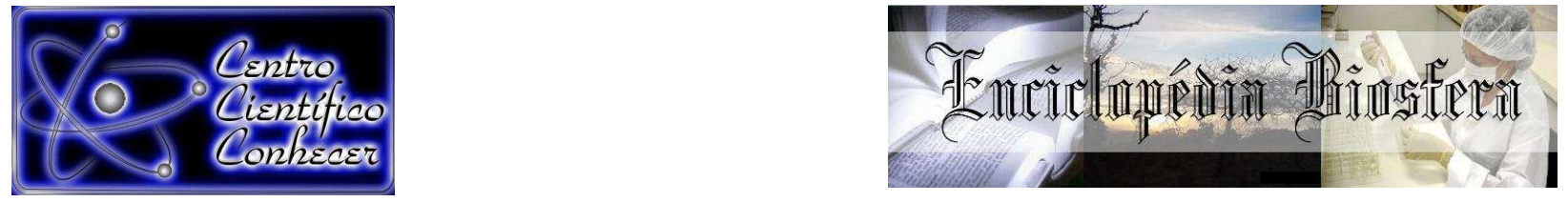

\title{
DESEMPENHO DA CULTURA DO MILHO SUBMETIDO A SISTEMAS CONSERVACIONISTAS E RESIDUAL DE GESSO
}

\author{
Leandro Alves Freitas ${ }^{1}$, Luiz Malcolm Mano De Mello², Élcio Hiroyoshi Yano ${ }^{3}$, \\ Donário Silva Teixeira ${ }^{4}$, Eduardo Takano Masunari ${ }^{5}$ \\ ${ }^{1}$ Mestrado, Faculdade de Engenharia, UNESP/Iha Solteira - SP, Brasil, \\ leandroalvesfreitas@hotmail.com; \\ ${ }^{2}$ Professor Titular, Faculdade de Engenharia, UNESP/IIha Solteira - SP; \\ ${ }^{3}$ Professor Assistente, Faculdade de Engenharia, UNESP/Ilha Solteira - SP; \\ ${ }^{4}$ Graduando Faculdade de Engenharia, UNESP/Ilha Solteira - SP; \\ ${ }^{5}$ Graduando Faculdade de Engenharia, UNESP/Ilha Solteira - SP.
}

Recebido em: 08/09/2015 - Aprovado em: 14/11/2015 - Publicado em: 01/12/2015 DOI: http://dx.doi.org/10.18677/Enciclopedia_Biosfera_2015_126

\section{RESUMO}

Com a intensificação do preparo do solo, os atributos físicos e químicos do solo foram sendo alterados conforme o manejo aplicado. Com o intuito de estudar os atributos agronômicos da cultura do milho nos diferentes manejos de solo e uso do gesso foi realizado este trabalho na área experimental da fazenda de Pesquisa e Extensão UNESP, Campus de Ilha Solteira - SP. O delineamento experimental foi de blocos ao acaso, combinando de quatro sistemas de cultivo: Semeadura Direta Contínua (SPD-SPD) e Alternada (SPD-CM), Cultivo Mínimo Continuo (CM-CM) e Alternado (CM-SPD) com ou sem o uso de gesso. Foram avaliadas as características agronômicas da cultura do milho. Os resultados demonstram que o gesso deve ser utilizado em função do manejo empregado, pois possui diferentes dinâmicas junto aos sistemas manejo do solo. O sistema de plantio direto continuo proporcionou os maiores valores para a população inicial, índice de sobrevivência, e massa de grãos, contudo não obteve incremento matéria seca (M.S) e na produtividade de grãos (P.G). Os maiores valores para estas variáveis foram obtidos no plantio direto alternado (PD-CM), fato pode ser explicado devido algum impedimento físico na área.

PALAVRAS - CHAVE: gesso agrícola, manejo do solo, Zea mays

\section{PERFORMANCE OF CULTURE SUBMITTED MAIZE CONSERVATIONISTS SYSTEMS \& GYPSUM RESIDUAL}

\begin{abstract}
With the intensification of soil preparation, physical and chemical soil properties were being changed as management applied. In order to study the agronomic traits of maize in different management of soil and use of gypsum was carried out this work in the experimental farm area of Research and Extension UNESP, Ilha Solteira - SP. The experimental design was a randomized block design, combining four farming systems: direct sowing Continuous (SPD-SPD) and alternating (SPD-CM), Minimum Cultivation Continuo (CM-CM) and Alternate (CM-SPD) with or without the use of plaster. The agronomic characteristics of maize were evaluated. The results show that the gypsum should be used in the employee management function, because it has different dynamic near the soil management systems. The tillage system still ENCICLOPÉDIA BIOSFERA, Centro Científico Conhecer - Goiânia, v.11 n.22; p. 856 2015
\end{abstract}


provided the highest values for the initial population, survival rate, and grain yield, but did not get increased dry matter (DM) and grain yield (PG). The highest values for these variables were obtained in the alternate tillage (NT-CM), can be explained because some physical impediment in the area.

KEYWORDS: gypsum, soil management, mays Zea

\section{INTRODUÇÃO}

A expansão agrícola no cerrado obteve grande sucesso, movida por diversos fatores como a correção do alumínio tóxico, a mecanização, a topografia das áreas agrícolas e regime de chuva. Nestes sistemas de cultivo intensivo as formas de manejo adotado acabaram influenciando os atributos do solo e a dinâmica dos nutrientes disponíveis as plantas (GONÇALVES, 2010).

Os sistemas de preparo do solo podem afetar os seus atributos químicos, físicos e biológicos e conseqüentemente, a viabilidade dos sistemas de produção (DEBIASI, 2013). Outro efeito negativo associado à mobilização excessiva do solo é o aumento da taxa de decomposição dos resíduos vegetais (GONÇALVES, 2010) e de mineralização da matéria orgânica. Geralmente esse processo é agravado pelo constante uso de implementos e tráfego agrícola utilizados no preparo. A utilização de sistemas de manejo de solo considerados como conservacionistas, estão sendo adotadas por vários produtores, pois o intenso manejo convencional acelerou a degradação dos recursos naturais (SEKI et al., 2010).

As limitações encontradas pelos técnicos e produtores em manter o grande potencial produtivo em alguns sistemas conservacionistas são os impedimentos físicos, e químicos do solo devido á compactação e correção de camadas sub superficiais considerados fatores adversos para o desenvolvimento da planta. (FRANCHINI et al., 2011; DEBIASI et al., 2011) demostraram a formação de camadas compactadas em Latossolos no sistema de plantio direto normalmente na camada de 0,10-0,20m.

A aplicação de gesso agrícola possibilita melhores condições do subsolo, podendo atuar, de certa forma, como descompactante do solo (RAlJ, 2008), proporcionando um ambiente que geralmente é favorável às raízes. A formação de complexos químicos com o alumínio torna-o menos disponível para as plantas. Por ter alta solubilidade no solo, o gesso fornece rapidamente o cálcio, que pode ser lixiviado em profundidade, melhorando a fertilidade e aumentando a exploração das raízes. (ROSSETTO \& SANTIAGO, 2011).

Considerando a importância de se conhecer e entender a influência do manejo do solo combinado com o uso do gesso agrícola, realizou-se esse trabalho com os objetivos de avaliar os índices de produção na cultura do milho.

\section{MATERIAL E MÉTODOS}

O experimento vem sendo desenvolvido desde o ano 2010, para a safrinha de 2012 foi semeado o milho de inverno em sucessão a cultura da soja na área experimental da Fazenda de Ensino, Pesquisa e Extensão (FEPE) pertencente à Faculdade de Engenharia da Unesp, Campus de Ilha Solteira, localizada no município de Selvíria - MS, nas proximidades das coordenadas geográficas 2022' $S$ e 5122 ' W e altitude média ao redor de $335 \mathrm{~m}$. O solo foi classificado Latossolo Vermelho distroférrico, textura argilosa (EMBRAPA, 2013). O clima da região é do tipo Aw, definido como tropical úmido com estação chuvosa no verão e seca no inverno, segundo a classificação internacional de Köeppen, apresentando temperatura, precipitação pluvial e umidade relativa média anual de $24,5{ }^{\circ} \mathrm{C}, 1370$ 
mm e $64,8 \%$, respectivamente.

Os dados de precipitação pluvial, médias das temperaturas máxima, mínima e média durante o desenvolvimento do experimento estão apresentados na Figura 1.

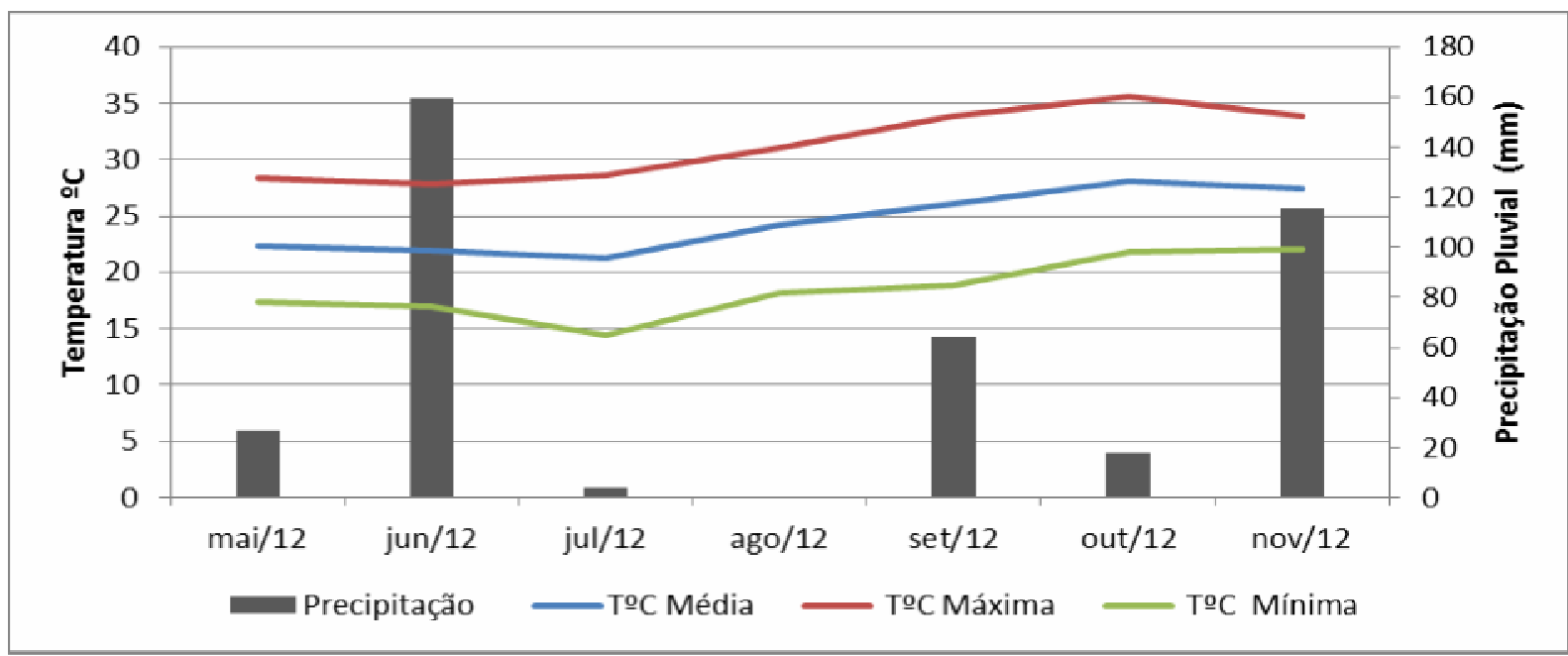

FIGURA 1 - Valores médios da precipitação pluvial $(\mathrm{mm})$, temperatura máxima, mínima e média $\left({ }^{\circ} \mathrm{C}\right)$ do período de maio de 2012 a novembro de 2012. Selvíria - MS

Fonte: Laboratório de Hidráulica e Irrigação, Faculdade de Engenharia - Unesp, Campus de Ilha Solteira.

O delineamento experimental empregado foi o de blocos casualizados em esquema fatorial $4 \times 2$, sendo quatro diferentes manejos de solo e uso ou não do gesso, constituindo se oito tratamentos e quarto repetições. Os tratamentos foram definidos pela combinação de quatro sistemas de cultivo: Plantio Direto Continuo (SPD - SPD), sempre feito o plantio direto com semeadura de precisão nas safras de verão e inverno, Cultivo Mínimo Continuo (CM - CM) feito nas safras de verão e inverno uma escarificação com o auxilio do implemento de subsolagem, Plantio Direto Alternado (SPD-CM) plantio direto com semeadura de precisão na safra de inverno e subsolagem no verão e Cultivo Mínimo Alternado (CM-SPD) subsolagem no inverno e semeadura de precisão no verão com e/ou sem gesso.

As parcelas foram constituídas de $325 / \mathrm{m}^{2}(25 \times 13 / \mathrm{m})$ e espaçadas de $0,45 \mathrm{~m}$, utilizando como área útil às três linhas centrais com 5 metros de comprimento. $A$ aplicação de calcário foi feita a lanço em área total de acordo com recomendação de solo na dose de $1 \mathrm{Ton} / \mathrm{ha}^{-1}$, o gesso foi aplicado na dose de $700 \mathrm{~kg} / \mathrm{ha}^{-1}$, somente no primeiro ano de plantio em novembro de 2010. As análises dos resultados foram processadas através do programa estatístico SISVAR (FERREIRA, 2003), realizando a comparação das médias pelo teste de Tukey, a 5\% de probabilidade.

Para a determinação dos Componentes de Produção na Cultura do milho foram avaliados da seguinte maneira:

Estande inicial e final: para estas avaliações foram contadas as plantas em três linhas centrais de cinco metros de cada parcela, a prolificidade foi determinado o numero de plantas com mais de uma espiga nas três linhas centrais em cinco metros de comprimento, para o Índice de sobrevivência foi feita a relação entre o Estande final e inicial e multiplicado por 100 , os valores obtidos foram extrapolados para o número de plantas ha ${ }^{-1}$.

A altura média das plantas de milho foi determinada pela medição, com régua graduada em centímetros, da distância entre o colo da planta até a extremidade apical em dez plantas por parcela, na época da colheita. Para a altura média da 
espiga foi adotada a distância entre o colo da planta e a inserção da espiga em dez plantas por parcela.

A massa seca de plantas de milho foi determinado através do corte de todas as plantas em cinco metros de comprimento, nas três linhas centrais, feito a pesagem da matéria verde total retirada uma amostra pesado a matéria verde, depois foi levado em estufa de ventilação forcada por 48 horas a $65^{\circ}$ graus retirado e pesado novamente a matéria seca da amostra, com isso pode se determinar a massa seca de plantas de milho estes valores foram extrapolados para um hectare.

A Massa de 100 grãos: foram contadas oito repetições de 100 grãos (BRASIL, 2009), cujas massas foram pesadas e ajustadas para $13 \%$ de teor de água, possibilitando estimar a massa de 100 grãos. Produtividade de grãos: para esta avaliação foram coletadas as plantas em cinco metros das três linhas centrais de cada parcela e submetidas à trilha mecânica e, após a debulha, foram pesados os grãos. A massa de grãos foi corrigida para o grau de umidade de $13 \%$ à base úmida e transformada para $\mathrm{kg} / \mathrm{ha}^{-1}$.

Em 2012 no cultivo de inverno foi semeado o milho em sucessão a cultura da soja de verão, os tratamentos com Cultivo Mínimo Continuo (CM - CM) e Plantio Direto Continuo (SPD - SPD), se mantiveram. Nos tratamentos com Cultivo Mínimo Alternado (CM - SPD) e Plantio Direto Alternado (SPD - CM) foi realizado o manejo do solo a cada safra na sucessão de milho no inverno (figura 2) e soja no verão (figura 3); constituindo se assim os diferentes tratamentos. Observa- se que sempre no inverno tem se o milho e no verão tem se a soja, e os diferentes tratamentos com o manejo de solo utilizado se mantêm nos dois anos agrícolas para as duas culturas.

\begin{tabular}{|c|c|c|c|}
\hline 32 & 31 & 30 & 29 \\
SPD-CM & CM - & SPD - & CM - CM \\
& SPD & SPD & \\
\hline 25 & 26 & 27 & 28 \\
SPD - & CM - & SPD - & CM - CM \\
CM & SPD & SPD & \\
\hline 24 & 23 & 22 & 21 \\
SPD - & CM - CM & SPD - & CM - \\
SPD & CM & SPD \\
\hline 17 & 18 & 19 & 20 \\
SPD - & CM - CM & SPD - & CM - \\
SPD & CM & SPD \\
\hline 16 & 15 & 14 & 13 \\
CM - CM & SPD - & CM - & SPD - \\
\hline 9 & CM & SPD & SPD \\
\hline CM - CM & SPD - & CM - & SPD - \\
\hline 8 & CM & SPD & SPD \\
\hline SPD - & CM - & SPD - & CM - CM \\
CM & SPD & SPD & \\
\hline 1 & 2 & 3 & 4 \\
SPD - & CM - & SPD - & CM - CM \\
CM & SPD & SPD & \\
\hline
\end{tabular}

\begin{tabular}{|c|c|c|c|}
\hline 32 & 31 & 30 & 29 \\
CM - & SPD - & SPD - & CM - CM \\
SPD & CM & SPD & \\
\hline 25 & 26 & 27 & 28 \\
CM - & SPD - & SPD - & CM - CM \\
SPD & CM & SPD & \\
\hline 24 & 23 & 22 & 21 \\
SPD - & CM - & CM - & SPD - \\
SPD & CM & SPD & CM \\
\hline 17 & 18 & 19 & 20 \\
SPD - & CM - & CM - & SPD - \\
SPD & CM & SPD & CM \\
\hline 16 & 15 & 14 & 13 \\
CM - CM & CM - & SPD - & SPD - \\
\hline 9 & 10 & 11 & 12 \\
SPD & CM & SPD \\
\hline CM - CM & CM - & SPD - & SPD - \\
\hline 8 & 7 & 6 & 5 \\
CM - & SPD - & SPD - & CM - CM \\
SPD & CM & SPD & \\
\hline 1 & 2 & 3 & 4 \\
CM - & SPD - & SPD - & CM - CM \\
SPD & CM & SPD & \\
\hline
\end{tabular}

FIGURA 2: croqui do cultivo de milho inverno FIGURA 3: croqui do cultivo de soja verão 


\section{RESULTADOS E DISCUSSÃO}

$\mathrm{Na}$ tabela 1 estão os vários modelos de seqüências de manejos de solo somente a prolificidade (P.L) obteve diferença significativa, com os maiores valores Cultivo mínimo continuo (CM-CM) e Plantio direto alternado (PD-CM), fato considerando prejudicial, pois ao pensamos que o melhoramento genético tem buscado plantas com somente uma espiga de forma que estas possuam um tamanho e numero de grãos maiores ao invés de varias gemas laterais produzindo órgãos vegetativos secundários, terciários, com desperdício de energia metabólica e produção de fitomassa. Mesmo sem a diferença significativa pode observar que no sistema de plantio direto continuo (PD-PD) a população final - P.F, Índice de sobrevivência - I.S (\%), altura de plantas - A.P $(\mathrm{m})$, diâmetro de colmo -D.C $(\mathrm{mm})$ foram obtidos os maiores valores

TABELA 1 - Valores médios obtidos no milho para população inicial - P.I e população final - P.F, ( $n^{\circ}$ de plantas ha $\left.{ }^{-1}\right)$, Índice de sobrevivência - I.S (\%), altura de plantas A.P $(m)$, diâmetro de colmo - D.C $(\mathrm{mm})$ e prolificidade - $(\mathrm{PL})$ em função do manejo de solo e o uso de gesso.

\begin{tabular}{|c|c|c|c|c|c|c|}
\hline \multirow{2}{*}{ Manejo } & P.I & P.F & 1.5 & A.P & D.C & P.L \\
\hline & \multicolumn{2}{|c|}{$\left(\mathrm{ha}^{-1}\right)$} & (\%) & (cm) & $(\mathrm{mm})$ & \\
\hline PD-PD & $57036,3 a$ & $57036,3 a$ & $94,5 a$ & $1,60 a$ & $26,10 a$ & $0,67 \mathrm{~b}$ \\
\hline CM-CM & 57036,5 a & $52036,5 \mathrm{a}$ & $86,8 \mathrm{a}$ & $1,58 \mathrm{a}$ & $25,63 \mathrm{a}$ & $0,81 a$ \\
\hline PD-CM & $57142,2 \mathrm{a}$ & $50581,2 a$ & $88,8 \mathrm{a}$ & $1,63 a$ & $26,50 \mathrm{a}$ & $0,85 a$ \\
\hline CM-PD & $58271,0 \mathrm{a}$ & $52345,2 \mathrm{a}$ & $89,7 \mathrm{a}$ & $1,62 \mathrm{a}$ & $25,65 \mathrm{a}$ & $0,67 \mathrm{~b}$ \\
\hline DMS & 3774,0 & 4625,2 & 14,3 & 0,2 & 2,85 & 0,13 \\
\hline \multicolumn{7}{|l|}{ Gesso $=\mathrm{G}$} \\
\hline Com & 58425,3 a & $52221,6 \mathrm{a}$ & $89,5 \mathrm{a}$ & $1,62 \mathrm{a}$ & $26,21 \mathrm{a}$ & $0,76 a$ \\
\hline Sem & $56573,4 \mathrm{~b}$ & $52314,2 \mathrm{a}$ & $90,5 \mathrm{a}$ & $1,59 a$ & $25,68 \mathrm{a}$ & $0,73 a$ \\
\hline DMS & 1988 & 2436,4 & 7,54 & 0,100 & 1,5 & 0,06 \\
\hline \multicolumn{7}{|l|}{ Tratamento } \\
\hline$M$ & $0,42^{\text {n.s }}$ & $1,23^{\text {n.s }}$ & $0,77^{\text {n.s }}$ & $0,16^{\text {n.s }}$ & $0,30^{n \cdot s}$ & $7,5^{\star *}$ \\
\hline G & $4,47^{\star}$ & $0,006^{n \cdot s}$ & $0,06^{\text {n.s }}$ & $0,53^{\text {n.s }}$ & $0,53^{n . s}$ & $0,67^{\text {n.s }}$ \\
\hline$M^{*} G$ & $0,53^{n, s}$ & $0,37^{\mathrm{n}, \mathrm{s}}$ & $1,58^{\mathrm{n}, \mathrm{s}}$ & $0,18^{\text {n.s }}$ & $0,11^{\text {n.s }}$ & $1,10^{\text {n.s }}$ \\
\hline Media geral & 57406,8 & 52267,9 & 90,03 & 1,6 & 25,94 & 0,75 \\
\hline CV (\%) & 4,75 & 6,39 & 11,49 & 9,01 & 7,94 & 12,6 \\
\hline
\end{tabular}
diferem entre si pelo teste de Tukey $(p<0,05)$.

Provavelmente no sistema de plantio direto á uma maior quantidade de matéria seca na superfície do solo responsável pela manutenção da umidade, melhores condições de temperatura e uniformidade na distribuição das sementes com isso uma maior uniformidade na emergência e desenvolvimento inicial e final do milho, aumentado a possibilidade de sobrevivência. COSTA et al. (2003) verificou que em sistemas de manejo de solos conservacionistas obteve uma redução de $13 \%$ nos valores máximos de temperatura em comparação com sistema de manejos convencionais. Segundo a EMBRAPA (2013) o plantio direto possui interação entre o menor revolvimento de solo e o escorrimento superficial melhorando na dinâmica da infiltração de agua no solo, reduzindo assim a erosão. Possui característica de manutenção e estabilidade dos agregados, evitando a compactação sub-superficial, aumenta a disponibilidade de agua e mantem a matéria orgânica. 
Estas características também podem ter reflexos no diâmetro de colmo (D.C) e na altura das plantas (A.P), ressaltando que estas características são reflexos de plantas mais nutridas, com possibilidade de melhores desenvolvimento e produtividade.

Em relação ao gesso somente a população inicial (P.I) demonstrou diferença significativa com os maiores valores quando utilizou o gesso (Tabela 1). Este fato se deve as características do gesso que provavelmente pode ter atuado junto ao calcário e feito a correção do alumínio tóxico, e com isso uma melhor disponibilidade de nutrientes como o $(\mathrm{Ca})$ e $(\mathrm{Mg})$ e $(\mathrm{k})$ aumentando assim o estande inicial. Trabalhando com doses de gesso, (ROSA JUNIOR; VITORINO, 1994; ROSA JUNIOR et al., 2006) concluíram que a gessagem pode atuar como condicionador das estruturas do solo, favorecendo a agregação, e conseqüente melhoria na estrutura do solo.

TABELA 2 - Valores médios obtidos para a massa seca de milho- M.S ( $\left.\mathrm{kg} / \mathrm{ha}^{-1}\right)$, massa de 100 grãos - M.G (g) e produtividade de grãos - P.G ( $\mathrm{kg} \mathrm{ha}^{-1}$ ) em função dos diferentes manejos de solo e gesso.

\begin{tabular}{cccc}
\hline \multirow{2}{*}{ Manejo } & M.S & M.G & P.G \\
\cline { 2 - 4 } & $\left(\mathbf{k g} / \mathbf{h a}^{-1}\right)$ & $(\mathbf{g})$ & $\left(\mathbf{k g} / \mathbf{h a}^{-1}\right)$ \\
\hline PD-PD & $5477,1 \mathrm{~b}$ & $18,4 \mathrm{a}$ & $1443,7 \mathrm{~b}$ \\
CM-CM & $5236,5 \mathrm{~b}$ & $16,8 \mathrm{ab}$ & $1730,0 \mathrm{a}$ \\
PD-CM & $6802,8 \mathrm{a}$ & $15,7 \mathrm{~b}$ & $1842,2 \mathrm{a}$ \\
CM-PD & $5958,3 \mathrm{~b}$ & $17,8 \mathrm{ab}$ & $1508,8 \mathrm{~b}$ \\
\hline DMS & 730,7 & 2,51 & 212,5 \\
\hline Gesso $=\mathbf{G}$ & & & \\
\hline Com & $5661,5 \mathrm{a}$ & $17 \mathrm{a}$ & $1645,3 \mathrm{a}$ \\
Sem & $6023 \mathrm{a}$ & $17,6 \mathrm{a}$ & $1596,3 \mathrm{a}$ \\
\hline DMS & 384,9 & 1,32 & 111,9 \\
\hline Tratamento & & & \\
\hline M & $12,6^{\star *}$ & $3,22^{*}$ & $11,35^{\star *}$ \\
G & $3,7^{\text {n.s }}$ & $0,92^{\text {n.s }}$ & $0,81^{\text {n.s }}$ \\
M ${ }^{\star} G$ & $9,5^{\star *}$ & $2,69^{\text {n.s }}$ & $21,33^{* *}$ \\
\hline Media geral & 5842,3 & 17,3 & 1620,8 \\
\hline CV (\%) & 9,03 & 10,49 & 9,47 \\
\hline
\end{tabular}

$(p<0,05) ;{ }^{* *}(p<0,01) ;{ }^{n, s}$ (não significativo). Médias seguidas de mesma letra não diferem entre si pelo teste de Tukey $(p<0,05)$.

SOUZA et al., (2010) trabalhando com plantio convencional e direto, com e sem uso do gesso, obteve maior estatura de milho na presença do efeito residual do gesso, pode ter sido mais pronunciado devido ao menor grau de adensamento do solo na presença desse condicionador, com a maior agregação do solo, conseqüentemente melhorando a estrutura ou ainda pelo favorecimento químico com a presença de cálcio melhorando as condições de distribuição do sistema radicular. $O$ efeito residual de gesso não proporcionou diferença significativa nas variáveis inserção de vagens, número de vagens, peso de 100 grãos e produtividade.

Durante o desenvolvimento da cultura deve ter ocorrido à lixiviação de alguns nutrientes como o cálcio $(\mathrm{Ca})$, magnésio $(\mathrm{Mg})$ para sub - superfície, com isso não 
diferença significativa entre o uso ou não do gesso. O sulfato presente no gesso movimenta-se no perfil até as camadas mais profundas (ZAMBROSI et al., 2007b; CAIRES, 2012), podendo ligar-se ao magnésio, formando assim o par iônico sulfato de magnésio (MgSO4), o qual é lixiviado no solo.

$\mathrm{Na}$ tabela 4 observa que os maiores valores para a massa seca (M.S) e produtividade de grãos foram obtidos no sistema de plantio direto alternado (PD$\mathrm{CM}$ ). Provavelmente como este trabalho vem sendo conduzido desde 2010 os melhores valores estão relacionados à maiores profundidades que poderiam estar compactadas, portanto como foi feita a escarificação na última safra pode propiciar melhores desenvolvimentos de plantas nesta safra, também pelo sistema de plantio direto ter por definição uma menor mineralização da matéria orgânica presente na superfície de solo, pois tem como definição o menor revolvimento de solo assim incrementando ainda mais os valores de massa seca (M.S). GONÇALVES. et al. (2010) trabalhando com o manejo do solo em plantio direto ocasionou uma decomposição de resíduos de milho e soja mais lenta que a da semeadura convencional, sendo que ao final do ciclo de estudo o plantio direto mostrou, aproximadamente, entre 16 a $17 \%$ a mais de resíduos.

Para a massa de grãos (M.G) os maiores valores foram obtidos no sistema de plantio direto continuo (PD-PD) (tabela 2), fato que pode ser explicado pelo índice de sobrevivência e população final de plantas $/ \mathrm{ha}^{-1}$, onde o valor no plantio direto continuo (PD-PD) foram muito mais expressivos, com isso obtemos uma maior numero de plantas por hectare o que será refletido na maior massa de grãos

O uso do gesso não demonstrou diferença significativa para massa seca (M.S), massa de 100 grãos (M.G) e produtividade de grãos (P.G) (tabela 2).

TABELA 3 - Valores médios obtidos no desdobramento da Prolificidade - (P.L) e massa de 100 grãos - M.G(g) para os manejos de solo e gesso.

\begin{tabular}{ccccc}
\hline \multirow{2}{*}{ Manejo } & \multicolumn{2}{c}{ P.L } & \multicolumn{2}{c}{ M.G (g) } \\
\cline { 2 - 5 } & \multicolumn{2}{c}{ Gesso } & \multicolumn{2}{c}{ Gesso } \\
\cline { 2 - 5 } & com & sem & com & sem \\
\hline PD-PD & $0,66 \mathrm{aB}$ & $0,68 \mathrm{aA}$ & $17,43 \mathrm{aA}$ & $19,55 \mathrm{aA}$ \\
CM-CM & $0,84 \mathrm{aAB}$ & $0,78 \mathrm{aA}$ & $15,45 \mathrm{aA}$ & $18,29 \mathrm{bAB}$ \\
PD-CM & $0,93 \mathrm{aA}$ & $0,80 \mathrm{aA}$ & $16,12 \mathrm{aA}$ & $15,49 \mathrm{aB}$ \\
CM-PD & $0,68 \mathrm{aB}$ & $0,67 \mathrm{aA}$ & $18,42 \mathrm{aA}$ & $17,11 \mathrm{aAB}$ \\
\hline
\end{tabular}

Médias seguidas de mesma letra, minúsculas nas linhas e maiúsculas nas colunas não diferem entre si pelo teste de tukey $(p<0,05)$.

Não se obteve diferença significativa com ou sem o uso do gesso para a prolificidade entre os mesmos sistemas de manejo, mas entre os manejos observa se maiores valores no plantio direto alternado (PD-CM) e menores no plantio direto continuo (PD-PD), demonstrando então que para esta variável o manejo junto ao gesso tem comportamento distintos. Devemos atentar que este fato tem uma grande importância, pois dependendo do manejo adotando poderemos ter uma maior ou menor prolificidade, e quanto maior esta característica mais prejudicial será ao pensarmos em plantas com uma única espiga e tamanho uniforme.

Para a massa de grãos (M.G) os maiores valores foram obtidos no cultivo mínimo alternado (CM-PD) e no plantio direto continuo (PD-PD) com e sem uso do 
gesso respectivamente. Provavelmente no cultivo mínimo alternado (CM-PD) a haste do subsolador pode ter levado o gesso em sub - superfície, e este podendo infiltrar os íons como $\mathrm{Ca}, \mathrm{K}, \mathrm{Mg}$ e $\mathrm{P}$, com isso estes nutrientes ficando indisponíveis. Segundo DIAS et al. (1992) a descida do $\mathrm{SO}_{4}$ através do perfil levaria os cátions $\mathrm{Ca}$ e Mg em maior quantidade, seguido por K, aumentando a V\% (saturação por bases) no subsolo.

TABELA 4 - Valores médios obtidos no desdobramento da massa seca - (M.S) produtividade grãos - P.G(g) para os manejos de solo e gesso.

\begin{tabular}{|c|c|c|c|c|}
\hline \multirow{3}{*}{ Manejo } & \multicolumn{2}{|c|}{ M.S (kg ha $\left.{ }^{-1}\right)$} & \multicolumn{2}{|c|}{ P.G (kg ha $\left.{ }^{-1}\right)$} \\
\hline & \multicolumn{2}{|c|}{ Gesso } & \multicolumn{2}{|c|}{ Gesso } \\
\hline & com & sem & com & sem \\
\hline PD-PD & 5324,2 aA & $5630 \mathrm{aB}$ & $1717 \mathrm{aA}$ & $1170 \mathrm{bC}$ \\
\hline CM-CM & 5891,5 aA & $4581,5 \mathrm{bC}$ & 1917 aA & $1542,2 \mathrm{bB}$ \\
\hline PD-CM & $5968,3 \mathrm{bA}$ & 7428,7 aA & $1812 \mathrm{aA}$ & 1865 aA \\
\hline CM-PD & $5563,4 \mathrm{bA}$ & 6452 aAB & 1270 bA & $1808 \mathrm{aAB}$ \\
\hline
\end{tabular}

Médias seguidas de mesma letra, minúsculas nas linhas e maiúsculas nas colunas não diferem entre si pelo teste de tukey $(p<0,05)$.

O uso do gesso não proporcionou diferença significativa entre os manejos para a matéria seca (M.S) e produtividade de grãos (P.G), contudo nota se maiores valores sem o uso do corretivo nos manejos alternados (tabela 4). Provavelmente 0 gesso pode atuar nas propriedades do solo de forma a descompactá-lo ou na melhor disponibilidade de nutrientes em perfil, pois sua aplicação junto ao calcário pode carregar íons em sub superfície corrigindo o alumínio tóxico e disponibilizando nutrientes. Em trabalhos com aplicação de condicionadores OLIVEIRA, (2013) concluiram que por ter alta solubilidade no solo, o gesso fornece rapidamente 0 cálcio, que pode ser lixiviado em profundidade, melhorando a fertilidade e aumentando a exploração das raízes.

A aplicação de gesso agrícola possibilita melhores condições do subsolo, podendo atuar, de certa forma, como descompactante do solo (RAIJ, 2008). Por ter alta solubilidade no solo, o gesso fornece rapidamente o cálcio, que pode ser lixiviado em profundidade, melhorando a fertilidade e aumentando a exploração das raízes. (ROSSETTO \& SANTIAGO, 2011).

Em relação aos melhores valores sem o uso do gesso nos manejos alternados, tal fato pode ser explicado pela forma de condução dos tratamentos, já que a cada 12 meses a área é manejada com uma escarificação, com isso a maior profundidade cerca de 0,30 a $0,40 \mathrm{~m}$ de solo que poderiam ter algum tipo de impedimento físico são rompidas.

Contudo MORAES (2013), relata que em sistemas com escarificação periódica do solo, a prática da subsolagem é dispensável, pois causa o rompimento nas estruturas dos agregados estáveis do solo, não favorece incrementos de produtividade de grãos em relação aos sistemas sem revolvimento do solo. FRANCHINI et al. (2011), relatam que a escarificação nem sempre resulta em benefícios ao desenvolvimento das culturas, os autores observaram que a escarificação periódica do SPD a cada três anos, associada à rotação de culturas, aumentou significativamente a produtividade da soja em relação ao SPD contínuo em apenas uma de 21 safras avaliadas. 
SILVA et al. (2012) em trabalho de longa duração relatam um curto período residual do efeito da escarificação do solo, onde os autores identificaram que após a realização da escarificação não houve diferenças na camada de 0,20-0,30 m em relação ao SPD contínuo.

\section{CONCLUSÃO}

Em relação ao manejo do solo sem o uso do gesso pode se determinar que o plantio direto contínuo contribuiu para os melhores valores para os índices de produtividade da cultura do milho, então maiores valores nas populações inicial, final, índice de sobrevivência e massa de grãos, contudo este não teve efeito na produtividade, fato explicado pela recente implantação do sistema.

As várias formas e métodos de manejo do solo junto à gessagem tiveram por finalidade melhorar as características do solo e produtividade da cultura do milho, porem neste trabalho não pode identificar um melhor manejo junto ao gesso, pois o condicionador possui comportamento distinto a cada tipo de manejo do solo.

Portanto, deve-se realizar estudados com trabalhos com longo período de observação, pois as variáveis ficaram muitos instáveis em relação aos diferentes manejos junto ao gesso.

\section{REFERÊNCIAS}

BRASIL. Ministério da Agricultura, Pecuária e Abastecimento. Regras para análise de sementes. Brasília, DF: Mapa/ACS, 2009. 395 p.

CAIRES, E. F. Calagem e uso de gesso em sistema plantio direto. Revista Plantio Direto, Passo Fundo, v. 128 p. 11, 2012.

COSTA, F. S.; ALBUQUERQUE, J. A.; BAYER, C.; FONTOURA, S. M. V.; WOBETO, C.Propriedades físicas de um Latossolo Bruno afetadas pelos sistemas plantio direto e preparo convencional Revista Brasileira de Ciência do Solo, Viçosa, MG, v. 27, p. 527-535, 2003.

DEBIASI, H.; FRANCHINI, J. C.; CONTE, O.; BALBINOT JUNIOR, A. A.; TORRES, E.; SARAIVA, O. F.; OLIVEIRA, M. C.N. Sistemas de preparo do solo: trinta anos de pesquisas na Embrapa Soja. Londrina: Embrapa Soja, 2013. 72 p. (Documentos /Embrapa Soja, 342).

DEBIASI, H.; FRANCHINI, J. C.; OLIVEIRA, F. A.; MACHADO, T. M. Ajuste de grades amostrais para o mapeamento da resistência à penetração de um Latossolo Bruno. n: 83 INAMASU, R. Y.; NAIME, J. de M.; RESENDE, A. V. de; BASSOI, L. H.; BERNARDI, A. C. de C. (Ed.). Agricultura de precisão: um novo olhar. São Carlos: Embrapa Instrumentação Agropecuária, p.138-142, 2011.

DIAS, L.E. Uso de gesso como insumo agrícola. Seropédica: Embrapa - Centro Nacional de Pesquisa de Biologia -CNPBS, 6 p. (Comunicado Técnico 7) 1992.

EMPRESA BRASILEIRA DE PESQUISA AGROPECUÁRIA- EMBRAPA. Sistema brasileiro de classificação dos solos. $3^{a}$ Edição. Distritro federal, 2013. 353 p. 
FRANCHINI, J. C.; COSTA, J. M.; DEBIASI, H.; TORRES, E. Importância da rotação de culturas para a produção agrícola sustentável no Paraná. Londrina: Embrapa Soja, 2011.52p. (Embrapa Soja. Documentos 327).

FERREIRA, D. F. Programa de análises estatísticas (Statistical Analysis Software) e planejamento de experimentos. Lavras: Universidade Federal de Lavras, 2003. Software.

GONÇALVES, S. L.; SARAIVA, O. F.; FRANCHINI, J. C.; TORRES, E. Decomposição de resíduos de milho e soja em função do tempo e do manejo do solo. Londrina: Embrapa Soja, 2010. 19 p. (Embrapa Soja. Boletim de Pesquisa e Desenvolvimento, 23).

MORAES, M. T. Qualidade física do solo sob diferentes tempos de adoção e de escarificação do sistema plantio direto e sua relação com a rotação de culturas. 2013. 205 f. Dissertação (Mestrado em Ciência do Solo) - Universidade Federal de Santa Maria, Santa Maria, 2013

OLIVEIRA, F.S. Perspectivas do uso de gesso agrícola em cafezais no planalto de vitória da conquista-Bahia. 2013. 48 f Trabalho de Conclusão de Curso (Especialista) - Universidade Estadual do Sudoeste da Bahia, Vitoria da Conquista, 2013.

RAIJ, B.V. Gesso na agricultura. Campinas: Instituto Agronômico, 2008. 233p.

ROSA JÚNIOR, E. J.; MARTINS, R. M. G.; ROSA, Y. B. C. J.;CREMON, C. Calcário e gesso como condicionantes físico e químico de um solo de cerrado sob três sistemas de manejo. Pesquisa Agropecuária Tropical, Goiânia, v.36, p.37-44, 2006.

ROSSETTO, R.; SANTIAGO, A. D. Agencia Embrapa de Informação Tecnologica -Ageitec. 2011.

SEKI, A. S. Demanda energética e produtividade da soja e do milho em áreas de plantio direto e cultivo mínimo. 2010. $131 \mathrm{f}$. Tese (Doutorado em Agronomia/ Energia na Agricultura) - Faculdade de Ciências Agronômicas, Universidade Estadual Paulista, Botucatu, 2010

SILVA, S. G. C.; SILVA, A. P.; GIAROLA, N. F. B.; TORMENA, C. A.; SÁ, J. C. M.Temporary effect of chiseling on the compaction of a Rhodic Hapludox Under notillage. Revista Brasileira de Ciência do solo, Viçosa, v. 36, n. 2, p. 547-555, 2012.

SOUZA, F. R.; ROSA JUNIOR, E. J.; FIETZ, C. R.; BERGAMIN, A. C.; VENTUROSO, L. R.; ROSA, Y, B. C. J. Atributos físicos e desempenho agronômico da cultura da soja em um Latossolo Vermelho Distroférrico submetido a dois sistemas de manejos. Ciência e Agrotecnologia, Lavras, v. 34, n. 6, p. 1357-1364, 2010.

ZAMBROSI, F. C. B.; ALLEONI, L. R. F.; CAIRES, E. F. Aplicação de gesso agrícola 
e especiação iônica da solução de um Latossolo sob sistema plantio direto. Ciência Rural, Santa Maria, v. 37, p. 110-117, 2007b. 